\title{
Its Not about the Destination, Its about the Journey- Plotting 50 Years of Changing Clinical Trends in Plastic Surgery in a Public Sector Teaching Hospital
}

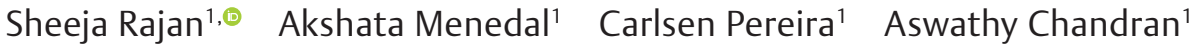 \\ Deepak Bhaskaran ${ }^{1}$ Najeeb Mohammad ${ }^{1}$ Bestin Thomas ${ }^{1}$ Aabha Das Sulochana ${ }^{1}$
}

${ }^{1}$ Department of Plastic and Reconstructive Surgery, Government Medical College, Kozhikode, Kerala, India
Address for correspondence Sheeja Rajan TM, MCh, DNB, Department of Plastic and Reconstructive Surgery, Government Medical College, Shrirang, PO Chevayur, Kozhikode, Kerala 673017, India (e-mail: sheejarajantm@gmail.com).

Indian J Plast Surg 2021;54:302-307.

\begin{abstract}
Background The year 2019 marked the 50th anniversary of plastic surgery department of our institution. We present an audit to plot the changing clinical trends in our work in the past five decades.

Methods A single-center retrospective cohort study based on the department demographics was performed and compared across the decades from 1969 to 2019.

Results In 1969, the relative proportion of reconstructive versus cosmetic surgery procedures was $94.32 \%$ versus $5.68 \%$; in 2019 this was $76.25 \%$ and $23.75 \%$, respectively. An increase of 22 times increase in outpatient registrations, 13.1 times in total surgeries, 642 times in trauma reconstruction, 290 times for hand surgeries, and 323 times for skin tumor surgeries was noted. Male patients (64.9\%) increased every decade more than females (35.1\%), mostly for trauma surgery and gynecomastia correction. Proportion of pediatric cleft patients have markedly decreased. Spectrum of surgical procedures have widened. Top five reconstructive surgeries in 2019 were limb trauma reconstruction, skin tumor surgeries, hand surgeries, arterio-venous fistula (AV) creation, and oculoplasty. The most common surgery performed was cleft lip

Keywords

- changing trends

- plastic surgery teaching

- surgical audit

- trauma reconstruction surgery in 1969 and hand surgery in 2019. The top five cosmetic surgeries performed in 2019 were scar revisions, nevus excision, liposuction and gynecomastia correction, rhinoplasty, and otoplasty.

Conclusions Data collection and archiving and periodic audits help us study changing trends in our field compared with the global trends. Knowing societal demands will help to improve the resident training in teaching hospitals.
\end{abstract}

\section{Introduction}

Plastic surgery in India is undergoing a sea of change. While there is a surge in the number of procedures all over the country, the demand for cosmetic surgery is also on the increase, carving a niche for India in health tourism sector. Though the

published online August 17, 2021
DOI https://doi.org/

$10.1055 / \mathrm{s}-0041-1729510$ ISSN $0970-0358$ specialty of plastic surgery boasts its humble origins from our country, this ancient wisdom somehow plunged into anonymity. Perhaps, it is time for Indian plastic surgeons to bring into practice the metaphor, "nanos gigantum humeris insidentes" (discovering truth by building on previous discoveries). It is important that current progress of plastic surgery in India
(C) 2021. Association of Plastic Surgeons of India

This is an open access article published by Thieme under the terms of the Creative Commons Attribution-NonDerivative-NonCommercial-License, permitting copying and reproduction so long as the original work is given appropriate credit. Contents may not be used for commercial purposes, or adapted, remixed, transformed or built upon. (https://creativecommons.org/licenses/by-nc-nd/4.0/).

Thieme Medical and Scientific Publishers Pvt. Ltd. A-12, 2nd Floor, Sector 2, Noida-201301 UP, India 
is meticulously archived and periodically audited by each center, so that we can constantly improve upon the accomplishments of our seniors. By this study, we have performed a retrospection into the work in our department for the past 50 years, in an attempt to plot the changing trends in plastic surgery at our center.

\section{Materials and Methods}

Plastic surgery work at Government Medical College, Kozhikode, Kerala, started on August 6, 1968, as a part of the General Surgery department, and gained independent status on August 7, 1980, as a 50-bed unit. The year 2019 marked the 50th anniversary of plastic surgeries being performed at this public sector tertiary care hospital of northern Kerala. We have performed a single-center retrospective cohort study based on the department demographics from the available operation theater notes records maintained by our residents, and patient case records retrieved from hospital medical record section, to plot the changing trends in plastic surgery in our institution. Data analysis of patient and distribution, top-performing surgeries, faculty, and resident demographics were compared across the decades from 1969 to 2019.

\section{Results}

\section{Patient Flow in the Department}

We noted a marked growth in outpatient department (OPD) Out patient department statistics over the last five decades, which was particularly pronounced in the last decade, that is, 22 times (-Fig. 1). New patient registrations per OPD have tripled every decade. Male patients (64.9\%) increased every decade more than females (35.1\%), mostly for trauma reconstruction (84\%), but a relative rise for cosmetic surgery, especially for gynecomastia correction, was also noted. Minor surgical procedures done in the OPD procedure room decreased, in preference to more day care surgeries in minor operation theater for added safety. Despite the 13.2 times increase in surgeries performed in the last decade (-Fig. 2) and more operating days, proportionate increase in day care surgeries, and early discharges have helped to manage the

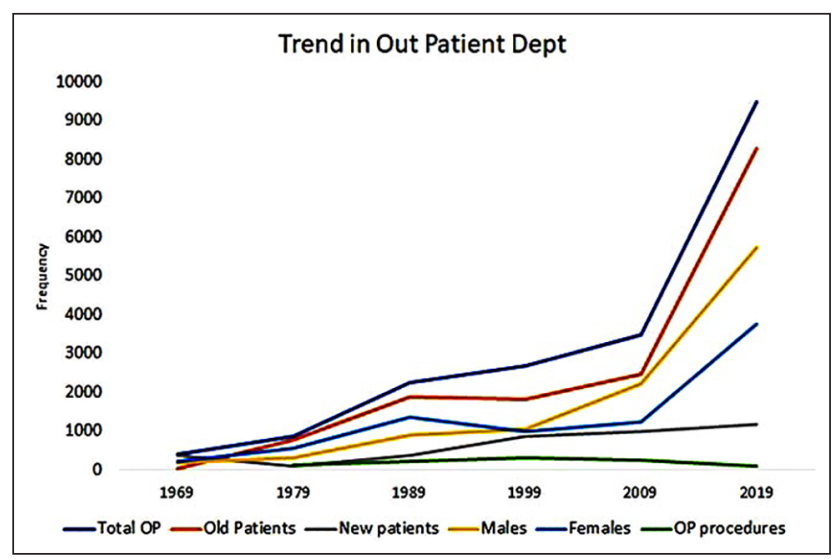

Fig. 1 Trends in outpatient demographics.

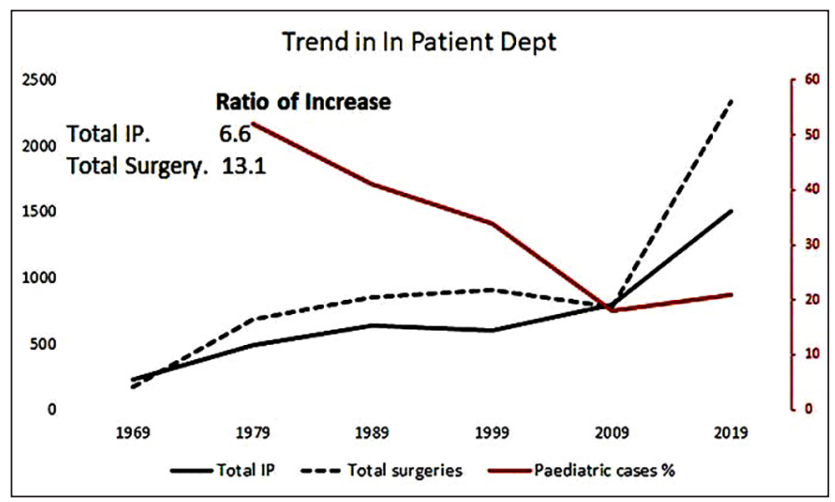

Fig. 2 Trends in inpatient demographics.

average inpatient load to 50 beds at any given time. Pediatric cleft patients have markedly decreased over the last two decades, attributed to load sharing and dedicated cleft centers in the city. Complicated clefts being referred have, however, increased. There is a steady increase in other types of pediatric cases, mostly congenital anomalies of hand and face, burn reconstruction, and trauma. Plastic surgery services in private hospitals in Kozhikode district have increased from none in 1969 to six in 2019.

\section{Changing Trends in Reconstructive Surgery}

The spectrum of plastic surgical procedures widened over the decades ( - Fig. 3). In the last two decades, while surgeries for chancrum oris, temporo-mandibular joint (TMJ) ankylosis, and vasovasostomy disappeared from the surgical list, new surgeries like replantation, revascularization, AV fistula creation, free-flap surgeries, and vaccum assisted closure (VAC) therapy have been entered. Trauma reconstruction and hand surgeries increased ( $\mathbf{- F i g . 4 a , b}$ ). The ratio of increase in surgeries from 1969 to 2019 is 642 times for trauma reconstruction, 290 times for hand surgeries, 323 times for skin tumor surgeries, 17.1 times for flap reconstructions, 7.6 times for burns contracture surgeries, and 0.07 times for cleft lip and palate surgeries.

While $69.6 \%$ of surgeries were done on referred patients from peripheral centers, a sharp increase was noted in the in-house referrals in the last decade. In 2019, this included referrals from departments of orthopaedics (limb trauma; $n=561$ ), dermatology (skin tumors and infections, morphea, vitiligo; $n=323$ ), otorhinolaryngology (facial trauma, rhinoplasty; $n=26$ ), ophthalmology (eyelid tumors, trauma, ptosis; $n=103$ ), oncosurgery (head and neck malignancy and sarcomas; $n=21$ ), general surgery (burns, diabetic foot, ulcers and difficult wounds, anal sphincter dehiscence; $n=235$ ), nephrology (AV fistula creation; $n=139$ ), physical medicine and rehabilitation (nerve palsies; $n=19$ ), pediatrics (syndromic children, vascular malformations; $n=31$ ), oral and maxillofacial surgery (jaw tumors and trauma; $n=$ 20), pedodontics (craniofacial or secondary cleft deformities; $n=4$ ), gynecology (wound dehiscence, rectovaginal fistulae, scar endometriosis, mullerian agenesis; $n=12$ ), cardiothoracic surgery (post coronary artery bypass grafting [CABG] 


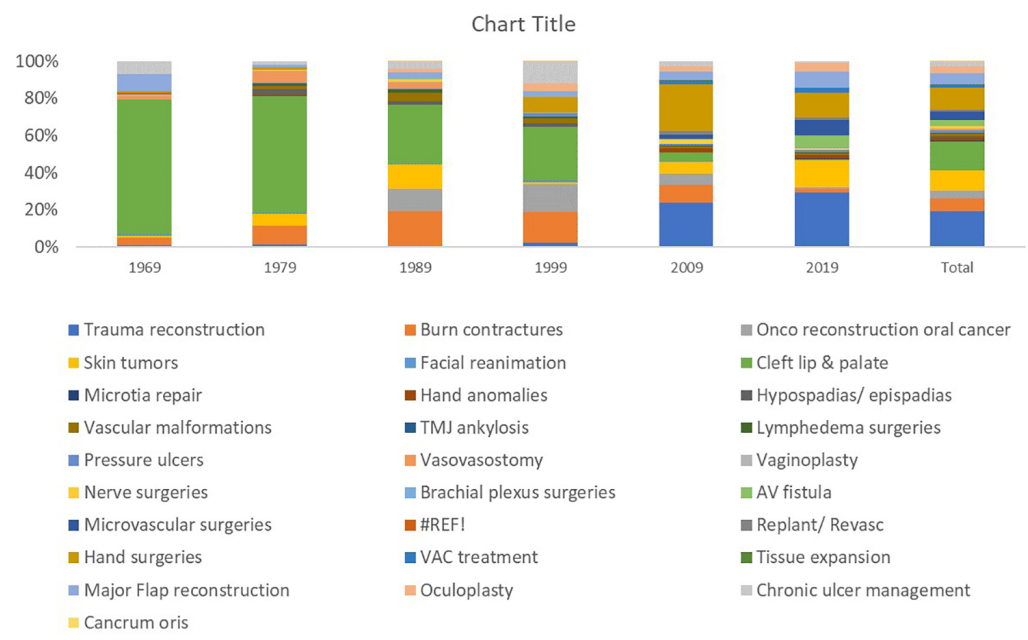

Fig. 3 Changes in spectrum of reconstructive surgery procedures.
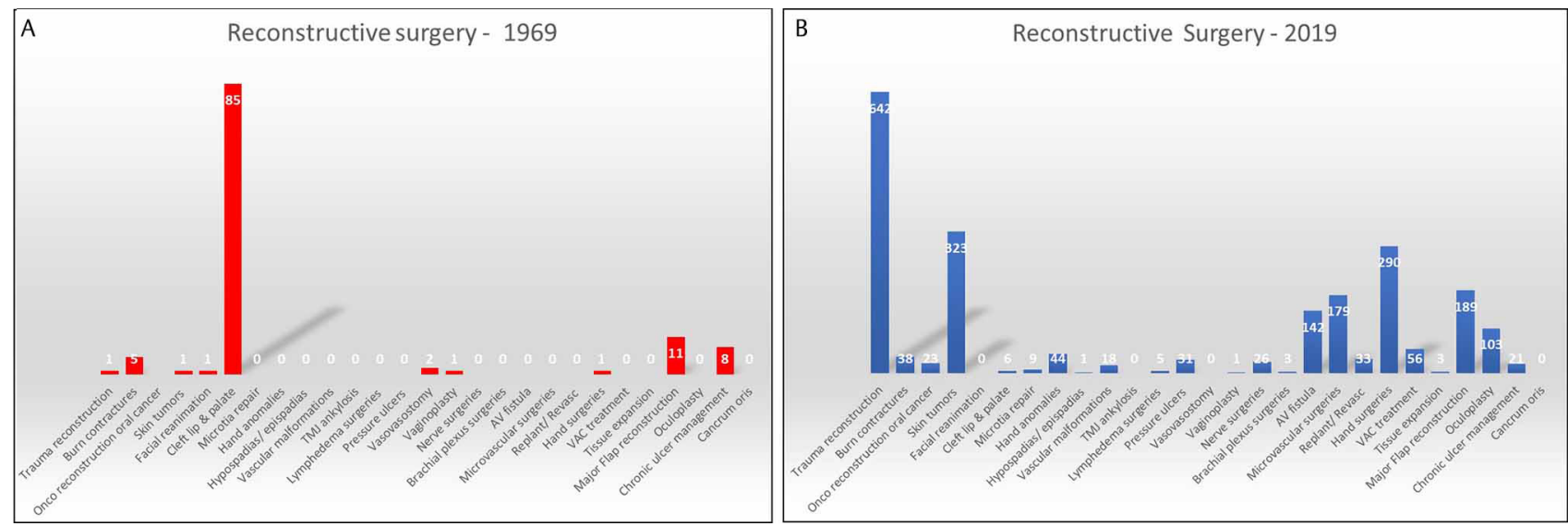

Fig. 4 (a) Reconstructive surgery procedures in 1969. (b) Reconstructive surgery procedures in 2019.

wound problems or chest wall reconstructions; $n=11$ ) and neurosurgery (meningomyelocele or head trauma; $n=8$ ), and occasionally from cardiology (extrusion of pacemakers; $n=$ 4 ) or general medicine (muscle or nerve biopsies, rheumatoid diseases; $\mathrm{n}=11$ ).

The top five reconstructive surgeries performed in 2019 were limb trauma reconstruction, skin tumor surgeries, hand surgeries, AV fistula creation, and oculoplasty. Whereas the most common surgery performed in 1969 was cleft lip surgery, in 2019 it was hand trauma reconstruction. The most common flaps done in 1969 were tube pedicle flaps; in 2019, they were finger flaps. Majority of the patients undergoing reconstructive surgeries were males (78\%) for limb trauma reconstruction following road traffic accidents, compared with females (32\%) who were operated for hand trauma, skin tumors, and burn contractures.

\section{Changing Trends in Cosmetic Surgery}

Increased demand for cosmetic surgery procedures was noted. In 1969, the relative proportion of reconstructive versus cosmetic surgery procedures was $94.32 \%$ versus $5.68 \%$, whereas in 2019 this was $76.25 \%$ and $23.75 \%$, respectively. Top five cosmetic surgeries performed in 2019 were scar revisions, nevus excision, liposuction and gynecomastia correction, rhinoplasty, and otoplasty ( - Fig. 5). The demand for scar revisions have increased by 155 times, liposuction by 50 times, otoplasty by 21 times, rhinoplasty by 10.7 times, and breast reduction by 7 times ( $\boldsymbol{-}$ Fig. $\mathbf{6 a}, \mathbf{b}$ ). Females seek cosmetic surgery more than males $(67 \%: 43 \%)$. There is a relative increase in males (14.6 times) in the last decade, mostly young men requesting gynecomastia correction and hair transplantation. Gynecomastia management, which used to be excision in 1970s, has changed to liposuction-gland excision after the department acquired a liposuction machine in 2002. Old procedures like dermofat have been replaced in the surgical list by fat grafting, platelet rich plasma (PRP) injections, liposuction, and breast augmentation with implants in the last decade. There is a subtle increase in clientele for breast surgeries, mostly for breast reduction and few implant-based augmentations. There are not many patients opting for breast reconstructions at our center despite mastectomy being the third most common procedure done in our general surgery department. 


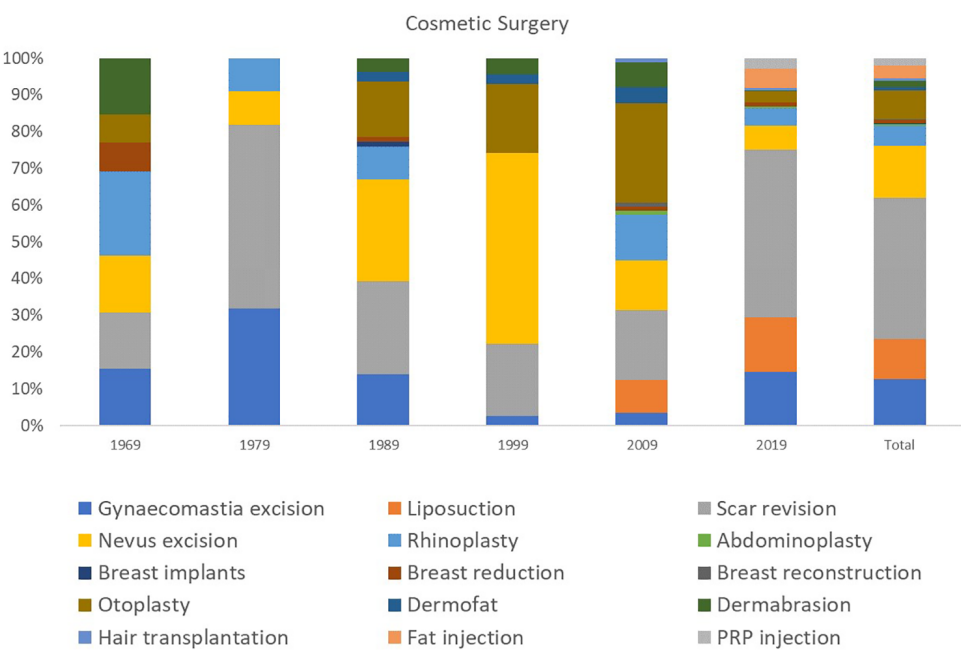

Fig. 5 Changes in spectrum of cosmetic surgery procedures.
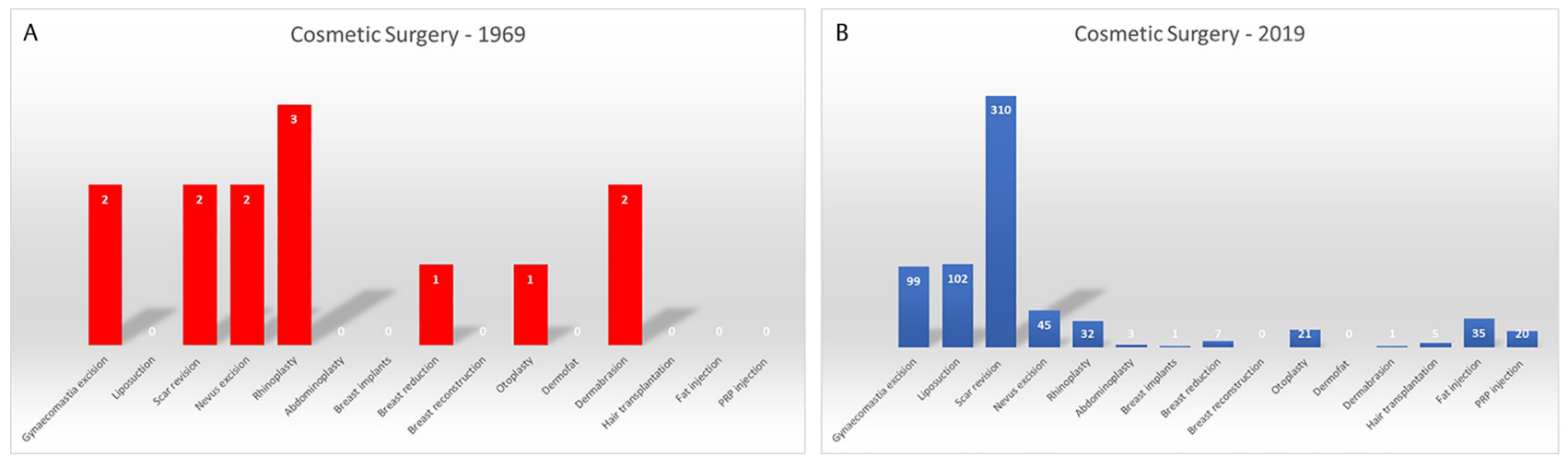

Fig. 6 (a) Cosmetic surgery procedures in 1969. (b) Cosmetic surgery procedures in 2019.

\section{Faculty and Resident Characteristics}

Fifty-three residents graduated from this institution with the first batch of two residents joining for 2-year $\mathrm{MCh}$ course in 1980 to 1982 . Three-year residency was started 2001 onwards. In 1982, 1983, and 1986, one seat lay vacant but no MCh seats were vacant since 2012. Additional post MCh training was sought by nine residents who pursued fellowships in cosmetic surgery $(n=2)$, hand surgery $(n=3)$, microvascular surgery $(n=3)$, and craniofacial surgery $(n=1)$. Four have pursued exclusive work in subspecialties (cosmetic surgery $n=3$, hand surgery $n=1$ ). Fifty-one percent graduates are working in teaching units and the rest in private sector. Among the residents, 42 were male and 11 were female; the number of female residents has increased in the last decade. There was a total of 36 peer-reviewed research publications in national and international journals and 2 ongoing funded research projects from the department. Despite the increasing work demands, faculty posts have not been increased to meet the increased patient load.

\section{Discussion}

Data assimilation is hard work and most plastic surgeons tend to shy away from this burden. Freshwater, ${ }^{1}$ in his study on the future of Plastic surgery data collection, commented that
"Plastic surgeons being visual creatures, thrive on visual data and not mind-blowing rows of numbers." The scope of plastic surgery being very broad, there are appreciable differences among centers in the kind of procedures performed. Global variation in registries created by plastic surgeons in terms of disease pattern, socioeconomic concerns, health insurance, and the growth of corporate health sector is customary. To ensure accuracy of data validation, standards have to be set in each country for the benefit of future generations. The publication of the six-volume Agrawal's Textbook of Plastic, Reconstructive and Aesthetic Surgery from India maybe seen as a first step in this direction. ${ }^{2}$ Holcomb et $\mathrm{al}^{3}$ have stated several benefits of data pool for bench marking quality of care and improving education.

Our article explores and audits the progress of plastic surgery in a public sector tertiary care teaching hospital over the past five decades. The patient load in our department and surgeries performed have markedly increased, especially in the last decade. This increment becomes more significant when we consider the fact that unlike the other states, Kerala has a decline in decadal growth rate from 26.33 in 1961-71 to 4.9 in the present decade, as per the state planning board report. ${ }^{4}$ The factors which have contributed to the increased patient influx might be our increasing involvement in emergency trauma cases, emergency and elective hand cases, as well as 
due to a rise in cosmetic surgery cases. Opening of the specialty clinics for hand surgery and cosmetic surgery in 2018 has also increased our consultations. The senior author has published 12 articles in popular magazines and newspapers and given awareness talks in media regarding plastic surgery. Poster exhibitions are held in OP reception area every year along with plastic surgery day celebrations. Conscious efforts were also made to increase in-house referrals by increasing faculty and resident interactions. Several talks were given about the scope of plastic surgery and areas of possible collaboration in doctors' forums as well in other medical and surgical departments. Resident rotations in plastic surgery were encouraged from eight departments. Suturing skill training was initiated on behalf of the plastic surgery department for undergraduates, and quiz programs and talks in student social media platforms were also organized in the last few years. Therefore, we may reasonably presume that our increasing patient load over the decades is due to heightened public and peer awareness about plastic surgery through advocacy.

Records show that much of our initial work was in cleft lip and palate, burns management, and facial reconstruction. Professor Goleria ${ }^{5}$ describes the origins of plastic surgery department at King Edward Memorial hospital in 1961, with the workload largely constituted by cleft surgeries. Mukund Thatte $^{6}$ has summarized the results of his "padhayatra on e-mail" in his Gillies oration 2012 as to changing trends in Indian plastic surgery from 1981 to 2011, based on the data collected from multiple teaching hospitals across the country. There was a huge increase in total amount of work over 30 years, with diversification into microsurgery, brachial plexus, and aesthetic surgery, but with dwindling number of cleft surgeries in all medical colleges except PGIMER Chandigarh. Similar trends were noted in our records over the past 50 years.

Predominant work at our center is focused on reconstructive surgery but lately cosmetic surgeries are increasing. In 2018, specialty clinics for cosmetic surgery and hand surgery were initiated to widen the spectrum of surgeries performed by us.

Singhal et $\mathrm{al}^{7}$ noted the essential role of plastic surgeons in trauma care centers, working in collaboration with other departments, thereby saving limbs and lives, and reducing morbidity. Records show that in 2019, we received referrals from 16 clinical departments, emphasizing our role as a "problem-solving specialty" in the hospital. In our center, trauma reconstruction supersedes any other plastic surgical procedures. Semer et $a l,{ }^{8}$ in 2010 , noted that surgical diseases contribute to $11 \%$ of global disease burden, a significant part of which can be ameliorated with plastic surgical expertise. But plastic surgeons have not been major players so far due to lack of public awareness. Peterson et $\mathrm{al}^{9}$ mentioned the integral role of plastic surgeons in trauma due to their special expertise. In many developing countries interventions are primarily required for reconstructive needs in trauma, burns, and congenital anomalies. ${ }^{10-15}$

The spectrum of reconstructive surgery procedures is widening with the top five surgeries at our center being trauma reconstruction, skin tumor surgeries, hand surgeries, AV fistula creation, and oculoplasty, similar to American Society of Plastic Surgery (ASPS) 2018 statistics, ${ }^{16}$ where tumor removal, laceration repair, maxillofacial surgery, scar revision, and hand surgery topped the charts. But there are variations. Zuo et $\mathrm{al}^{17}$ report a waning interest in hand surgery training in the United States. This contrasts with our center which shows an increment in hand surgeries by 290 times in the last five decades. However, head and neck reconstructions performed in our center reduced, partly attributable to oncosurgeons partaking in reconstructions and plastic surgeons doing only more complex reconstructions, comparable to a study by Kozak et al. ${ }^{18}$ The study of such volume trends helped to address shortcomings in training curricula by ACGME (Accreditation council for graduate medical education $)^{19,20}$; similar measures may be adopted while revising curricular demands in residency programs in India.

Recent trends show increased demand for cosmetic surgery at our center. Aesthetic surgery was initially confined to scar revisions and occasional gynecomastia surgery though breast augmentations were also done in the 1970 s, as per our records. In 2019, the top five cosmetic surgery procedures performed by us were scar revisions, nevus excision, liposuction, rhinoplasty, and otoplasty. Holcomb ${ }^{3}$ in a gender specific review showed that males undergo fewer aesthetic procedures. Our study noted 14.6 times increase in males seeking cosmetic surgery, mostly for gynecomastia, scar revisions, and hair transplantation. This is comparable to the ISAPS $2018^{21}$ statistics where males most commonly underwent gynecomastia correction, liposuction, eyelid surgery, rhinoplasty, and otoplasty whereas females opted for breast augmentation, liposuction, eyelid, abdominoplasty, and breast lift. A striking contrast is the less frequency of breast reconstructions despite a high prevalence of breast cancer in Northern Kerala. Walker et $\mathrm{al}^{22}$ studied the tripartite influence of peers, parents, and media on female cosmetic surgeries. Sobanko, ${ }^{23}$ Salehahmadi et $\mathrm{al}^{24}$ Beghin, ${ }^{25}$ and Hamilton et $\mathrm{al}^{26}$ explored gender roles in cosmetic surgery. Despite the high female literacy in Kerala, social regulations of a patriarchal system might be postulated as a deciding factor for our patients.

Graduates from our center have found placements, with majority opting for private-sector nonacademic practice. In the recent years, they are getting further trained through fellowships in cosmetic, hand or craniofacial surgery. Sharma ${ }^{27}$ highlighted the need to redefine goals in clinical training to make residents "future-ready" to meet the needs of market forces. This means that demand-supply audits like Rohrich et $\mathrm{al}^{28}$ need to be performed in India also. No MCh seats have lain vacant in the past two decades at our institution. This maybe attributable to perceived demand of a specialty and competition for the training opportunities. There is a noticeable increase in female residents in plastic surgery in our center. Sinno ${ }^{29}$ and Atashroo et $\mathrm{al}^{30}$ stated that happy working conditions, high operative volume, faculty mentorship, and good research infrastructure attract plastic surgery applicants to a program. But comprehensive training from a single center is difficult because it has to overlap multiple specialties and involve predominantly reconstructive modules while incorporating aesthetic content also. Oni et $\mathrm{al}^{31}$ stated that only half of graduating plastic surgery residents feel comfortable integrating aesthetic surgery into 
their practice. Considering the current demand for cosmetic training in the domestic market as well as in health tourism sector in India, we must consider revamping the curriculum to include more cosmetic surgery elements. If plastic surgery in India is to meet global standards, more focus needs to be given to infrastructure building of teaching institutions and make teaching practice more attractive.

\section{Conclusion}

Periodic audits help us understand the trends in our field and compare it with the global picture. This will help to improve clinical competency of our residents, thereby creating job-ready young graduates. Only thus can we fortify the specialty of plastic surgery for future generations in India.

\section{Conflicts of Interest}

None declared.

\section{Acknowledgments}

The authors wish to acknowledge Dr Biju George for the data analysis and senior plastic surgeons Dr Mukund Thatte, Dr Surajit Bhattacharya, and Dr Hari Venkatramani for their valuable input while preparing the article.

\section{References}

1 Freshwater MF. The future of plastic surgery data collection, analysis and presentation. J Plast Reconstr Aesthet Surg 2016;69(6):864-868

2 Agrawal K, ed. Textbook of Plastic, Reconstructive and Aesthetic Surgery. Vol 1-6. 1st ed. Noida, India: Thieme,; 2017

3 Holcomb JD, Gentile RD. Aesthetic facial surgery of male patients: demographics and market trends. Facial Plast Surg 2005;21(4):223-231

4 Population-Economic review-State Planning Board Kerala 2016. Availabe it: Keralahttps://kerala.gov.in/ documents

5 Goleria KS, Rana RE. The history of the plastic surgery department, K.E.M. Hospital, Mumbai, India. Indian J Plast Surg 2004;37:136-142

6 Thatte M, The Flail Upper Limb Reconstruction and Restoration of Function. Lucknow, India: Sir Harold Gillies Oration APSICON, Compilation of Gillies Oration, Association of Plastic Surgeons of India; 2012

7 Singhal M, Naalla R, Dave A, Moumita De, Gupta D, Chauhan $\mathrm{S}$. The role of plastic and reconstructive surgeon in trauma care: perspectives from a level 1 trauma centre in India. Indian J Plast Surg 2018;51(2):170-176

8 Semer NB, Sullivan SR, Meara JG. Plastic surgery and global health: how plastic surgery impacts the global burden of surgical disease.JPlast Reconstr AesthetSurg 2010;63(8):1244-1248

9 Peterson SL, Moore EE. The integral role of the plastic surgeon at a level I trauma center. Plast Reconstr Surg 2003;112(5):1371-1375, discussion 1377-1378

10 Mishra B, Koirala R, Tripathi N, Shrestha KR, Adhikary B, Shah $S$, Plastic surgery-myths and realities in developing countries: experience from eastern Nepal. Plast Surg Int; 2011

11 Hacıkerim Karşıdağ S, Ozkaya O, Uğurlu K, Baş L. The practice of plastic surgery in emergency trauma surgery: a retrospective glance at 10,732 patients. Ulus Travma Acil Cerrahi Derg 2011;17(1):33-40

12 Jovic G, Corlew DS, Bowman KG. Plastic and reconstructive surgery in Zambia: epidemiology of 16 years of practice. World J Surg 2012;36(2):241-246
13 Goodacre TE. Plastic surgery in a rural African hospital: spectrum and implications. Ann R Coll Surg Engl 1986;68(1):42-44

14 Guzman KJ, Gemo N, Martins DB, et al. Current challenges of plastic surgical care in Sub-Saharan Africa (Maputo, Mozambique) Plast Reconstr Surg Glob Open 2018;6(8):e1893

15 KhanM,AzizA,NazS, etal.Plasticsurgical trauma:asingle-centre experience. Indian J Plast Surg 2012;45(3):538-545

16 American Society of Plastic Surgeons. 2018 plastic surgery Statistics report. https://www.plasticsurgery.org/documents/News/Statistics/2018/plastic-surgery-statistics-full-report-2018.pdf . Accessed March 31, 2020

17 Zuo KJ, Retrouvey H, Wanzel KR. Factors that affect medical students' perception and impression of a plastic surgery program. Ann Plast Surg 2019;82(2):224-228

18 Kozak GM. Katzel E, Rose JF, Wu LC. A disappearing act: trends in head and neck free flap reconstruction over the last decade. Plast Reconstr Surg Glob Open 2019;7:1

19 Accreditation Council for Graduate Medical Education (AGGME). Operative minimums effective July 1, 2014-review committee for plastic surgery. https:// www.acgme.org/ Portals/0/PFAssets/ProgramResources/ Operative_Minimums_ effective_07012014.pdf. Accessed March 31, 2020

20 Chung KC, Song JW, Shauver MJ, Cullison TM, Noone $\mathrm{RB}$; Directors of the American Board of Plastic Surgery. Certification examination cases of candidates for certification by the American Board of Plastic Surgery: trends in practice profiles spanning a decade (2000 to 2009) Plast Reconstr Surg 2011;128(2):568-576

21 International Society of Aesthetic Plastic surgery. ISAPS international survey on aesthetic/cosmetic procedures performed in 2018. https://www.isaps.org/wp-content/ uploads/2019/12/ISAPS-Global-Survey-Results-2018-new. pdf. Accessed March 31, 2020

22 Walker C.E, Krumhuber E.G, Dayan S. et al. Current Psychology 2019. Effects of social media use on desire for cosmetic surgery among young women. doi 10.1007/s12144-019-00282-1

23 Sobanko J, Taglienti A, Wilson A, et al. Motivations for seeking minimally invasive cosmetic procedures in an academic outpatient setting. Am Soc Aesthet Plast Surg; 2015; 35(8):1014-1020

24 Salehahmadi Z, Rafie SR. Factors affecting patients undergoing cosmetic surgery in Bushehr, southern Iran. World J Plast Surg 2012;1(2):99-106

25 Beghin JC, Teshome Y. Perfecting Beauty under the Knife: The Determinants of Global Cosmetic Surgery Consumption [working paper o. 14017]. Ames, IA: Iowa State University Department of Economics; 2014:1-29

26 Hamilton MM, Hobgood T. Emerging trends and techniques in male aesthetic surgery. Facial Plast Surg 2005;21(4):324-328

27 Sharma RK. Changing trends in plastic surgery training. Indian J Plast Surg 2014;47(2):162-166

28 Rohrich RJ, McGrath MH, Lawrence WT, Ahmad J; American Society of Plastic Surgeons Plastic Surgery Workforce Task Force. Assessing the plastic surgery workforce: a template for the future of plastic surgery. Plast Reconstr Surg 2010;125(2):736-746

29 Sinno S, Mehta K, Squitieri L, et al. Residency characteristics that matter most to plastic surgery applicants: a multi-institutional analysis and review of the literature. Ann Plast Surg 2015;74(6):713-717

30 Atashroo DA, Luan A, Vyas KS, et al. What makes a plastic surgery residency program attractive? An applicant's perspective. Plast Reconstr Surg 2015;136(1):189-196

31 Oni G, Ahmad J, Zins JE, Kenkel JM. Cosmetic surgery training in plastic surgery residency programs in the United States: how have we progressed in the last three years? Aesthet Surg J 2011;31(4):445-455 